\title{
OPTICAL AGTIVITY AND OPTICAL ROTATORY DISPERSION IN SYNTHETIC POLYMERS
}

\author{
P. Pino, P. Salvadori, E. Chielini and P. L. Luisi
}

Istituto di Chimica Organica Industriale dell'Università di Pisa, Centro Nazionale di Chimica delle Macromolecole del C.N.R., Pisa, Italy

Among the large number of methods proposed for the investigation of macromolecular conformation in solution, optical activity is in principle one of the most powerful since, in general, optical activity is strongly dependent on conformational equilibria ${ }^{1}$. Its use, however, is seriously hindered by the difficulty in calculating the optical activity even of small molecules theoretically. This difficulty can be partially solved in some cases by using a semi-empirical calculation of the optical rotation ${ }^{2}$; furthermore some information concerning the relationships between optical activity and conformation in polymers can be obtained by comparing the optical activity of polymers with that of low-molecular-weight models in which intermolecular interactions between the chromophoric systems responsible for the optical rotation can often be excluded.

From the experimental point of view the difficulties often encountered in preparing optically-active polymers are largely compensated by the fact that much information can be obtained using small quantities of polymer samples which are non-homogeneous with respect to molecular weight. In fact it has been shown ${ }^{3}$ that the molar rotatory power in synthetic polymers, if referred to one monomeric unit, is in general independent of molecular weight and molecular-weight distribution, at least for macromolecules containing more than about 20 monomeric units in which the influence of the terminal groups on the rotation can be neglected. For this reason the molar rotation at each wavelength in the papers concerning optically-active polymers is referred to single monomeric units instead of to entire macromolecules, ignoring all the problems connected with the molecular-weight distribution.

In the present paper we shall consider for some polymers and lowmolecular-weight models investigated in our laboratory, the origin of rotatory power, the influence of structure of monomeric units and stereoregularity on optical rotation, and finally, for the case of the poly- $\alpha$-olefins in hydrocarbon solution, we shall consider some relationships between molar optical rotation and conformation.

We shall not attempt to make a complete review of the data on this subject as reviews covering both experimental data $^{4}$ and theoretical aspects 5 have been published quite recently.

\section{GENERAL ASPEGTS OF OPTICAL AGTIVITY IN POLYMERS}

As in low-molecular-weight compounds, the optical rotation in polymers is connected with optically-active electronic transitions in definite chromo- 
phoric systems, which may be the same as in low-molecular-weight models, or can be modified by mutual interactions among the chromophoric systems existing in different monomeric units. In the first case the optical activity of the polymer, referred to a single monomeric unit, as far as electronic factors are concerned, should be about the same as in low-molecular-weight models, and the differences eventually found in optical rotation must be substantially attributed to different positions of the conformational equilibria in lowmolecular-weight models and in the monomeric units of the polymers. No direct information can be obtained in this case from the optical activity on the main-chain conformation; however, in some cases ${ }^{6}$ the respective position of the monomeric unit atoms inserted in the principal chain and respectively in the lateral chains can be established and hence the general features of the prevalent conformation of the main chain can be inferred.

In the second case the modification of the chromophoric systems present in the monomeric units can be directly related ${ }^{7}$ to the conformation of the main chain of the polymers; in this case the optical activity of the polymer, referred to a single monomeric unit, and of the low-molecular-weight models must be different even if the conformational equilibrium assumes in both cases similar positions.

A mutual interaction among the chromophoric systems present in different monomeric units of synthetic polymers has so far been detected principally in polyamino acids and has been related to the presence of a helical conformation of the main chain in solution ${ }^{8}$; however, this topic has been discussed elsewhere both from theoretical and experimental points of view and will not be considered here. Poly-(S)-4-methyl-1-hexyne ${ }^{9}$ (Ia) represents an extreme case of this type in which the chromophoric system in lowmolecular-weight model Ib (isolated double bond) and in polymer (partially-conjugated double bonds) is substantially different. However, in this case the polymer is not crystalline at room temperature and its structure has not been investigated by $\mathrm{x}$-ray diffraction; optical rotatory dispersion (o.r.d.) cannot be investigated below $450 \mathrm{~m} \mu$ because the ratio of optical rotation to absorption coefficient is too small; no circular dichroism (c.d.) measurements have been carried out until now and the only conclusion that can be drawn is that the main chain is not planar, the type of folding being unknown.

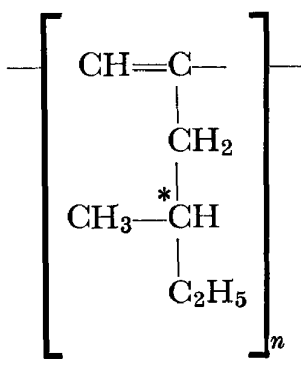

$\lambda_{\max }=230 \mathrm{~m} \mu \quad \log \epsilon_{\max }=3 \cdot 46$

$\lambda_{\max }=323 \mathrm{~m} \mu \quad \log \epsilon_{\max }=3 \cdot 48$

$[\Phi]_{\mathrm{D}}^{25}-22 \cdot 9$

Ia

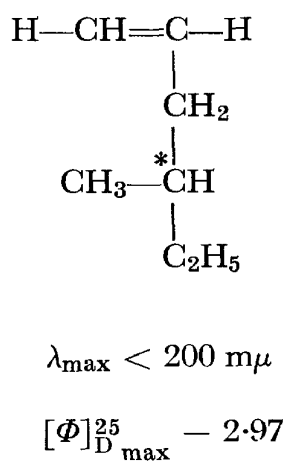

Ib 


\section{OPTICAL DISPERSION IN SYNTHETIC POLYMERS}

Two other cases are known in which the electronic transitions at the longest wavelength seem to be different in synthetic polymers and in the corresponding low-molecular-weight models; in the isotactic polyacrylamides a transiton at about $270 \mathrm{~m} \mu$ seems to exist in the polymer ${ }^{10}$ and not in the models ${ }^{10}$; in the isotactic polymethylmethacrylate, a maximum at $207 \mathrm{~m} \mu$, the intensity of which is strongly temperature-dependent, and two shoulders at 216.5 and $211.5 \mathrm{~m} \mu$ exist ${ }^{11}$ in the polymer while in the low-molecularweight saturated esters a band at about $204 \mathrm{~m} \mu$ without shoulders is normally present ${ }^{12}$.

However no optically-active compounds of this type have been investigated from the above point of view and therefore the possible relationships between molar rotation and conformation in the above series are unknown (see Note 1 added in proof on page 489 ).

In the series of vinyl polymers investigated by our group $6,13,14$ (II, III, IV) the wavelength of the optically-active transitions in the near u.v. seems not to be very different in the polymers (independent of their stereoregularity) and in the low-molecular-weight models, and no new bands at longer wavelengths have been found in the polymers.

The polymers which can be better investigated from this point of view are the polyvinyl ketones (II). As shown in Table 1 the $n \rightarrow \pi^{*}$ electronic transition connected with the existence of the $>\mathrm{C}=\mathrm{O}$ group is at the same wavelength for polymers having different stereoregularity, only the absorption
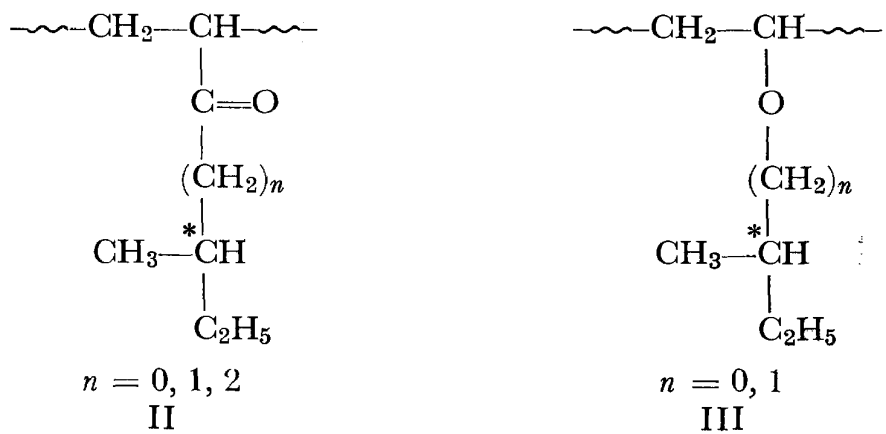

III
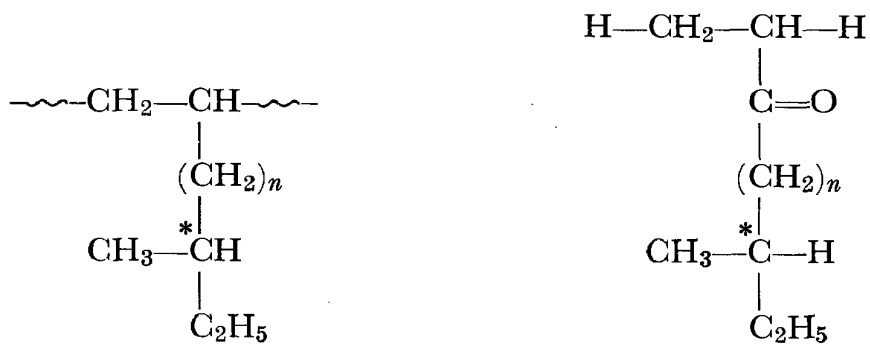

$$
n=0,1,2
$$

IV

$$
n=0,1,2
$$

coefficient being lower for the more stereoregular fraction. In comparison with the low-molecular-weight models the transition occurs in the polymers, 
P. PINO, P. SALVADORI, E. GHIELLINI and P. L. LUISI

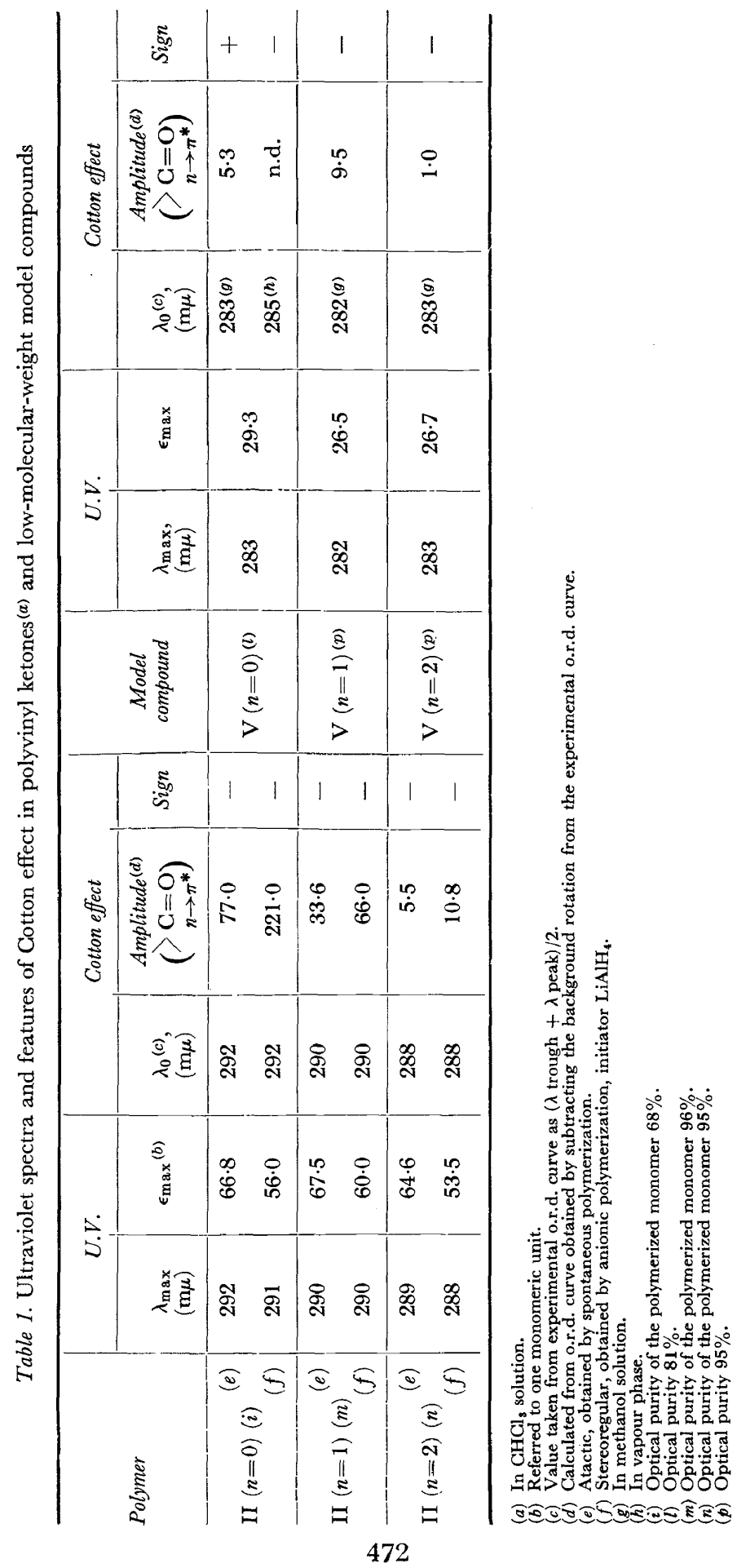




\section{OPTICAL DISPERSION IN SYNTHETIC POLYMERS}

according to the u.v. spectra, at a wavelength $6-8 \mathrm{~m} \mu$ higher; the absorption coefficient is about twice; practically independent of temperature between 25 and $60^{\circ} \mathrm{C}$. The above wavelength differences might be independent of interactions among $>\mathrm{C}=\mathrm{O}$ groups in the polymer and hence from the mainchain conformation; in fact ketonic compounds having the $>\mathrm{G}=\mathrm{O}$ transition at about $290 \mathrm{~m} \mu$ are known in the literature ${ }^{15}$. However, as far as the values of $\epsilon$ found in the polymer are concerned, they are close to the

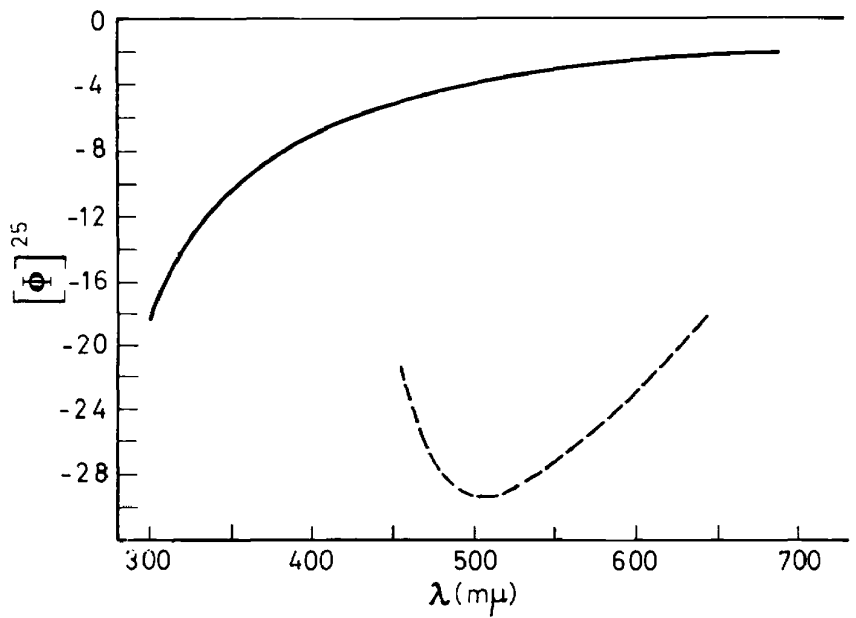

Figure 1. —— - o.r.d. curve of (S)-4-methyl-1-hexene (optical purity $92 \%$ ). — - o.r.d. curve of poly-(S)-4-methyl-1-hexyne (optical purity 89\%). Acetone ins., diethyl ether sol. fraction.

values found for acetonylacetone and could be connected with some type of unknown interaction between the keto groups, which might be dependent on the conformation of the principal chain.

In any case the large differences in optical activity observed in the more stereoregular fractions of polyvinyl ketones II $(n=0,1)$ and low-molecularweight models are mainly connected with the amplitude of the Cotton effects and hence with the position of the conformational equilibrium in the monomeric units of the polymers and in the models respectively.

In the case of polyvinyl ethers, Cotton effects cannot be detected with the spectropolarimeters at present available, and the deduction of the Cotton effect wavelength from the Drude equation is not advisable, as at least two chromophoric systems exist giving contributions of opposite sign to the rotation $^{16}$ (Figure 2). However u.v. spectra have shown that the band at the longest wavelength, which in [(S)-1-methylpropyl]-ethyl ether is optically active $^{16}$, is in the same region for the polymers (III, $n=0, \lambda_{\max }=190$; III, $\left.n=1, \lambda_{\max }=191\right)^{13}$ (1966), and for the corresponding low-molecularweight models ${ }^{16}$. Therefore, in this case, also interactions between the different chromophores present in the macromolecule should not play a very important role in determining the large rotation differences observed in some cases between polymers and models.

For poly- $\alpha$-olefins neither Cotton effect nor u.v. maxima could be detected 
with the experimental techniques used until now in our Institute; however in this case o.r.d. curves are simple up to $200 \mathrm{~m} \mu$ and the wavelength corresponding to the Cotton effect in polymers and models can be evaluated by using a one-term Drude equation.

As shown in Table 2, all the $\lambda_{0}$ found for polymers and models are between $165 \mathrm{~m} \mu$ and $179 \mathrm{~m} \mu$ showing that in this case also modifications of chromo-
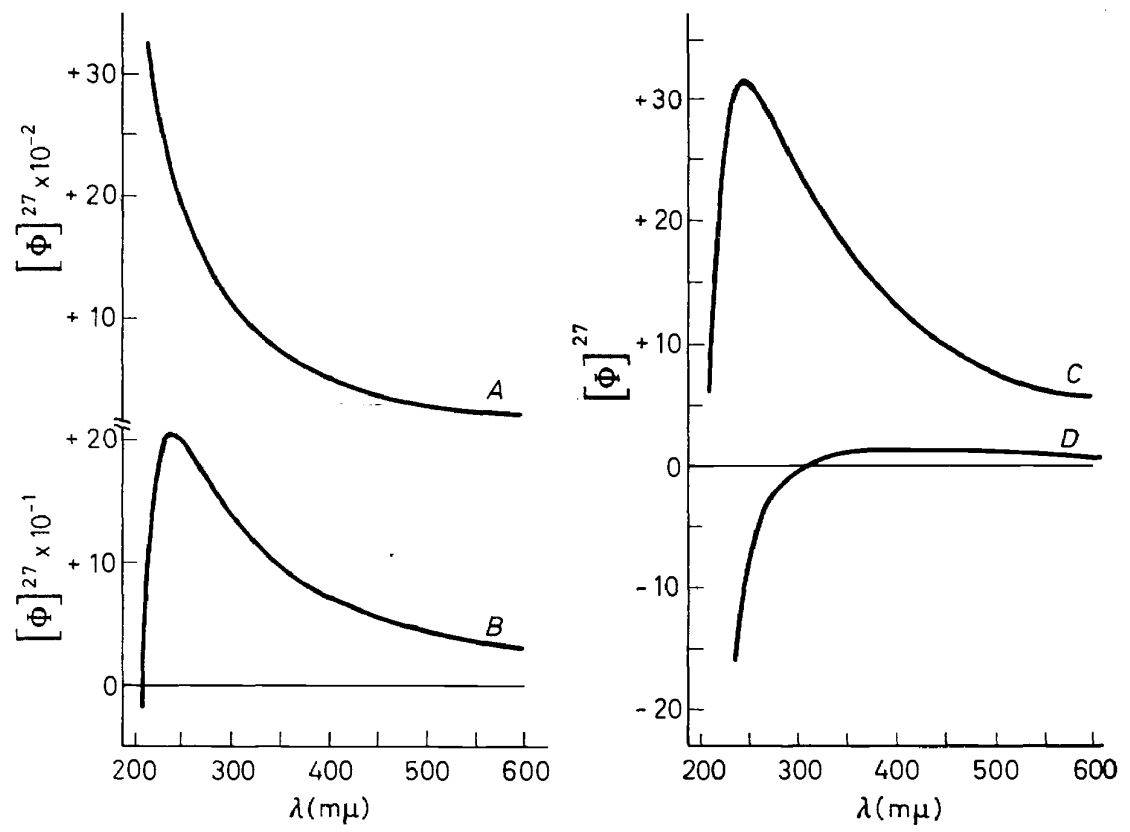

Figure 2. (A) o.r.d. curve of poly-[(S)-1-methyl-propyl]-vinyl-ether (monomer optical purity $\sim 90 \%$ ). Acetone ins., ether sol. fraction. $(B)$ o.r.d. curve of $[(\mathbf{S})$-1-methyl-propyl]ethyl ether (optical purity $80 \%$ ). (C) o.r.d. curve of poly-[(S)-2-methyl-butyl]-vinylether (monomer optical purity 99\%). Acetone ins., diethyl ether sol. fraction. (D) o.r.d. curve of $[(\mathrm{S})-2$-methyl-butyl]-ethyl ether (optical purity $99 \%$ ).

phoric systems should not be mainly responsible for the large rotation differences observed in some cases between polymers and models.

No systematic investigation has been carried out until now on the origin of rotatory power in polyacrylic derivatives. For atactic poly- $[(\mathbf{S})-2-$ methyl-butyl]-methacrylate we have found, contrary to some published data $^{17}$, a plain o.r.d. curve up to $250 \mathrm{~m} \mu$; the Cotton effect, corresponding to the known $n \rightarrow \pi^{*}$ transition in the low-molecular-weight esters, has been detected in the polymers ${ }^{20}, \lambda_{0}$ being located at about $215 \mathrm{~m} \mu$.

Also in the case of condensation polymers, with the exception of polyamino acids which are not considered in the present paper, no systematic investigations on o.r.d. have been published until now, and we shall consider only two examples which are at the present under investigation in our laboratory. Among the polyethers the polypropylene oxide VI has an anomalous o.r.d. curve with a maximum not corresponding to a Cotton 
OPTICAL DISPERSION IN SYNTHETIG POLYMERS

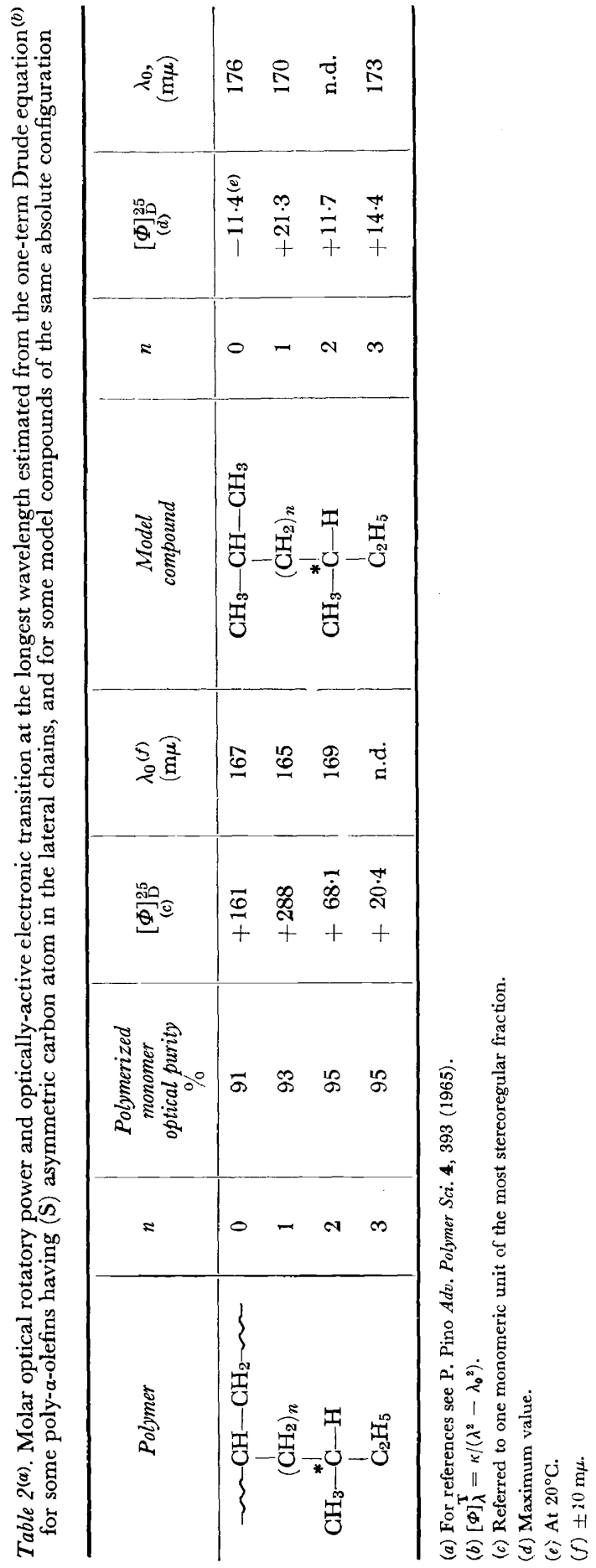


effect-at about $230 \mathrm{~m} \mu$ in diethyl ether ${ }^{18}$ analogous to that observed for the polyvinyl ethers. The u.v. spectra have not been investigated in this case.

Optical rotatory dispersion of poly-(-)-lactide (VII) has been investigated by R. C. Schulz ${ }^{19}$ and more recently by our group ${ }^{20}$ which has confirmed the maximum found by Schulz at $275 \mathrm{~m} \mu$.
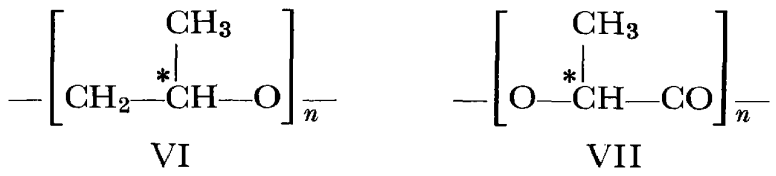

Furthermore a maximum at $220 \mathrm{~m} \mu$ has been found which corresponds to the first extremum of a Cotton effect having $\lambda_{0}$ at about $215 \mathrm{~m} \mu$ and attributable therefore to the known $n \rightarrow \pi^{*}$ optically-active transition of the -COOR* group. In this case too, no investigation of the u.v. spectra of polymers and models has been carried out (see Note 2 added in proof on page 490).

\section{RELATIONSHIPS BETWEEN OPTICAL ROTATION AND STRUGTURE IN SOME SYNTHETIC POLYMERS}

As optical rotation cannot at present be calculated theoretically, relationships between optical rotation and structure in polymers can be drawn only on an empirical or semi-empirical basis in series of homologous compounds.

In the field of optically-active synthetic polymers this discussion must be limited to the series of vinyl polymers ${ }^{6,13,14}$ in which at least two or three members of the series have been investigated as far as o.r.d., $[\Phi]$-stereoregularity and $[\Phi]$ polymers- $[\Phi]$ models relationships are concerned (Table 3).

As emphasized in previous publications ${ }^{6}$, in the case of poly- $\alpha$-olefins the following facts appear clearly: (1) the sign of rotation of the polymer is related to the absolute configuration of the asymmetric carbon atom present in the lateral chains; (2) the rotation referred to one monomeric unit at $589 \mathrm{~m} \mu$ and o.r.d. curves being simple, at all the wavelengths in the range investigated (above $200 \mathrm{~m} \mu$ ), is much higher in isotactic polymers than in the models when the asymmetric carbon atom of the lateral chains is in the $\alpha$ or $\beta$ position with respect to the principal chain. The rotation is higher but of the same order of magnitude, in the two cases, when the asymmetric carbon atom is in the $\gamma$ position and is practically the same when the asymmetric carbon atom is in the $\delta$ position with respect to the principal chain (Table 3).

As we shall discuss later these facts can be interpreted on the basis of conformational analysis which shows that, at least in the case of the poly- $\alpha$-olefins, when the asymmetric carbon atom of the lateral chains is in $\alpha$ or $\beta$ position with respect to the principal chain, few conformations of the monomeric units having high optical activity of the same sign prevail in the conformational equilibria. The conformational equilibrium position is entirely different in the case of the models shown in Table 3 in which no large prevalence of conformations having high rotatory power of the same sign can exist. The situation is the same in polymer monomeric units and 
OPTIGAL DISPERSION IN SYNTHETIC POLYMERS

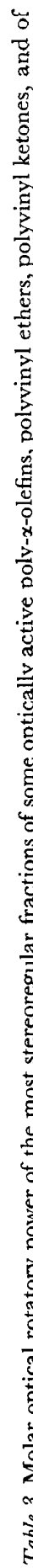

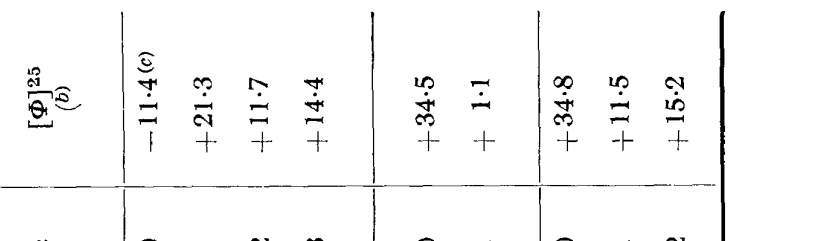

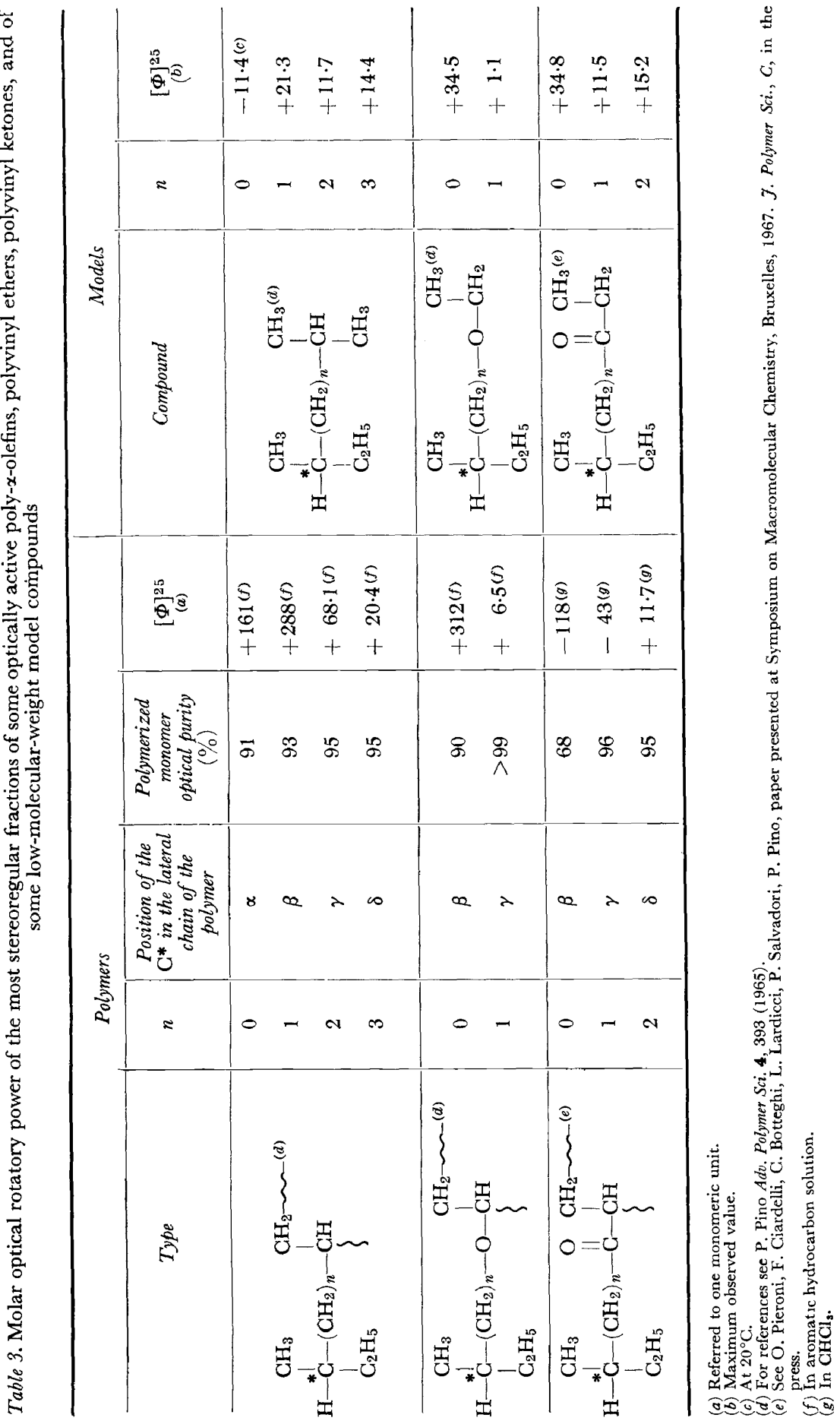


models when the asymmetric carbon atom in the lateral chains is in the $\delta$ position with respect to the principal chain while the case in which the asymmetric carbon atom is in the $\gamma$ position is an intermediate one.

The relationships between optical rotation and structure in the other two series are more complicated: in fact the rotation originated by the hydrocarbon backbone which can be connected in a rather simple way with the conformation, is strongly altered by the presence of other chromophoric groups such as ethereal oxygen or keto-groups. These chromophores absorb at longer wavelengths than the paraffins, and the related electronic transitions occurring in the asymmetric environment make remarkable contributions to the observed rotatory power. Unfortunately the relationships between the optical rotation connected with the oxygen-containing chromophores and conformation are not very well known in aliphatic compounds and this lack of knowledge makes the interpretation of the experimental data even more difficult.

This situation is clearly shown in the case of polyvinyl ketones in which the positive background at $589 \mathrm{~m} \mu$ arising from the transitions connected with the hydrocarbon backbone and from the $n \rightarrow \sigma^{* 21}$ transition of the keto groups is completely obscured by the negative Cotton effect corresponding to the $n \rightarrow \pi^{*}$ transition of the keto groups in II $(n=0)$ and II $(n=1)$, but is still apparent in II $(n=2)$. In this case the intensity of the above Cotton effect is much smaller because of the larger distance of the asymmetric carbon atom of the lateral chains from the carbonyl group and from the principal chain.

A similar situation exists in polyvinyl ethers in which the Cotton effect related to the presence of ethereal oxygen is not detectable by the available spectropolarimeters, but is certainly negative both in III $(n=0)$ and III $(n=1)$. In this case however, if we admit that the background rotation is substantially dependent on the hydrocarbon skeleton, we can conclude that a relationship between monomeric unit structure and conformational equilibria, similar to that observed in poly- $\alpha$-olefins, also exists in polyvinyl ethers.

Despite the above difficulties we believe that from the above data it can be concluded that, in optically-active linear vinyl polymers, a secondary butyl group in the $\alpha$ or $\beta$ position with respect to the principal chain considerably enhances the absolute value of the optical activity in comparison to the low-molecular-weight models. The enhancement is mainly related, at least in the cases examined up to now, to the largely different conformational equilibrium positions in the polymers and in the models.

\section{RELATIONSHIPS BETWEEN ROTATORY POWER AND STEREOREGULARITY IN VINYL POLYMERS}

The more detailed data on the relationship between stereoregularity and optical rotation concerns the series of poly- $\alpha$-olefins IV $(n=0,1,2,3)$. In this case $[\Phi]$ increases by increasing stereoregularity as evaluated by melting point, infrared analysis, and solubility data (Table 4).

As o.r.d. curves are plain and $\lambda_{0}$ of the Drude equation is independent of stereoregularity, the increase of $[\Phi]_{\mathrm{D}}$ must be connected with $K$ values of 
OPTIGAL DISPERSION IN SYNTHETIC-POLYMERS

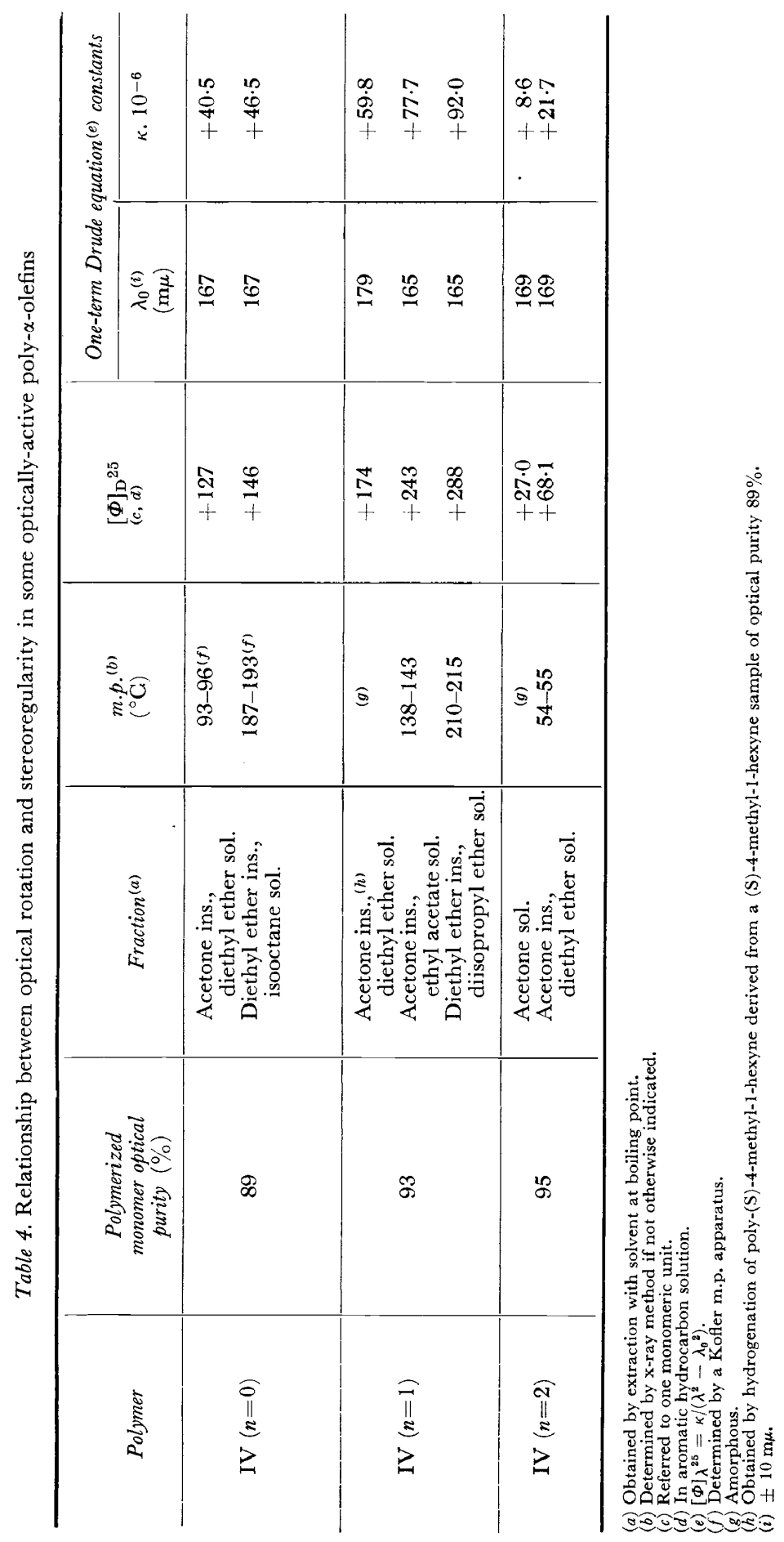


the Drude equation. As conformational analysis and semi-empirical calculation of optical activity indicate that configurational inversions in the main chain should not substantially affect $[\Phi]_{\mathrm{D}}$, at least for stereoblock polymers, the dependence experimentally found of $[\Phi]_{D}$ on stereoregularity could be attributed to the fact that, in samples with different stereoregularity, differences in conformational equilibria exist, in agreement with the statistical model assumed for the conformation of these relatively simple macromolecules as we shall discuss later ${ }^{3}$ (Luisi 1968).

The above considerations, drawn for the chromophoric system responsible for the rotation in the poly- $\alpha$-olefins on the basis of the Drude equation, hold also for $n \rightarrow \pi^{*}$ transition of the $>\mathrm{G}=\mathrm{O}$ chromophoric system in the $\alpha$ position with respect to the main chain in polyvinyl ketones.

As shown in Table 5, $\lambda_{0}$ of the Cotton effect is independent of stereoregularity but the amplitude of the Cotton effect is strongly affected by stereoregularity estimated on the basis of crystallinity in the case of II $(n=0)$

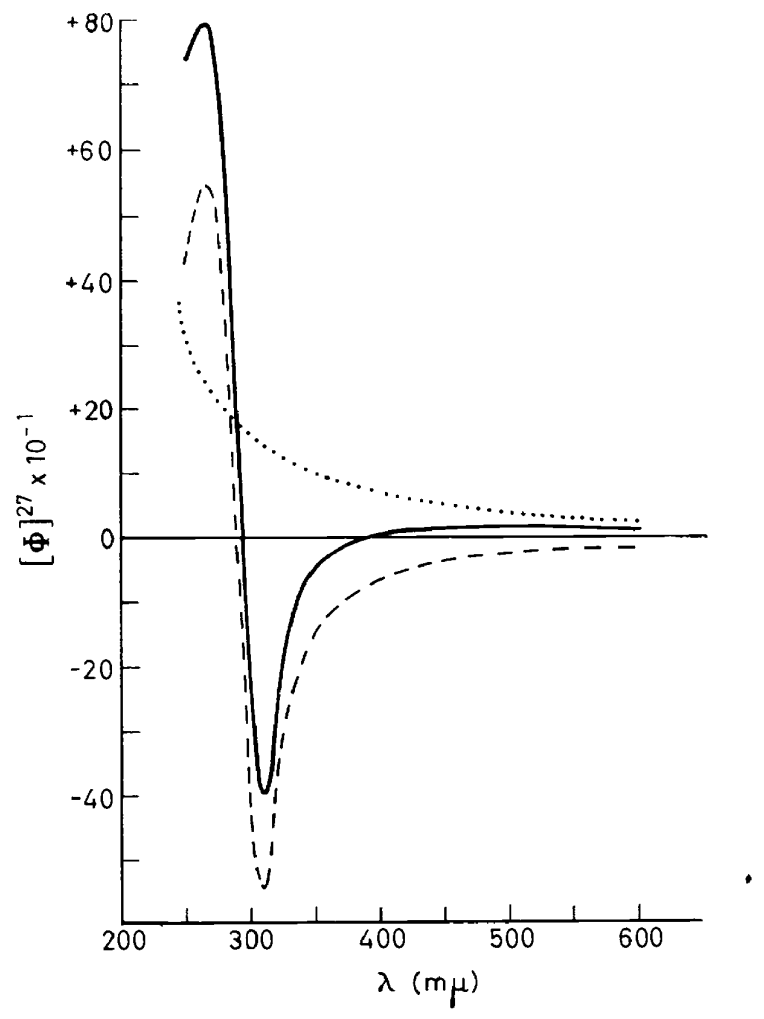

Figure 3. o.r.d. of poly-[(S)-3-methyl-pentyl]-vinyl-ketone Experimental curve; ........ Background rotation

- - Gotton effect calculated for $>\mathrm{G}=\mathrm{O} n \rightarrow \pi^{*}$ transition. 
OPTICAL DISPERSION IN SYNTHETIG POLYMERS

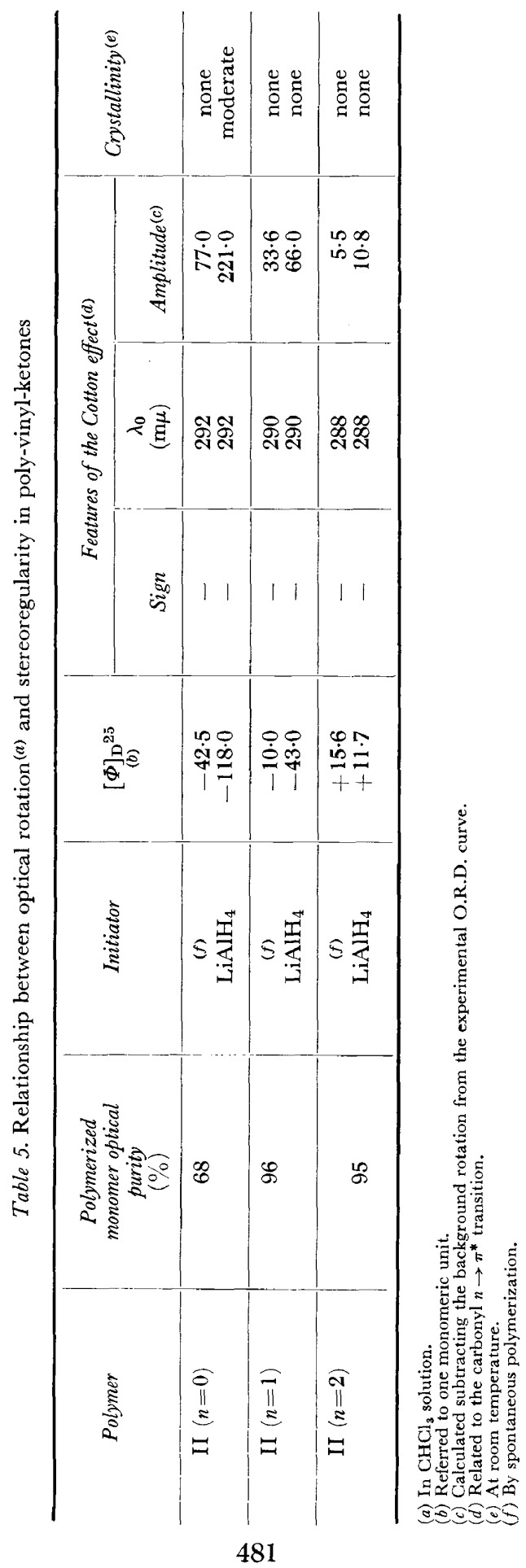


P. PINO, P. SALVADORI, E. CHIELLINI and P. L. LUISI

and on the basis of the stereospecificity of the polymerization process used for II $(n=1)$ and II $(n=2)$. The exception noted for II $(n=2)$ in which the absolute value of $[\Phi]_{\mathrm{D}}$ is higher for the less-stereoregular fractions is only apparent: in fact in this case the rotatory power measured is prevailingly given by the positive background rotation from which the contribution of the negative Cotton effect due to the $n \rightarrow \pi^{*}$ transition of the $>\mathrm{C}=\mathrm{O}$ group is subtracted. The absolute $[\Phi]_{\mathrm{D}}$ values found show that, by decreasing stereoregularity, the negative contribution given by the $n \rightarrow \pi^{*}$ transition of the $>\mathrm{C}=\mathrm{O}$ group decreases more than the positive contribution by the other chromophoric systems absorbing at a much lower wavelength (Figure 3).

In fact separating the contribution by the Cotton effect connected with the presence of $n \rightarrow \pi^{*}$ transition of the $>\mathrm{C}=\mathrm{O}$ from the background ${ }^{21}$, the contribution to the rotation by the $n \rightarrow \pi^{*}$ transition of $>\mathrm{C}=\mathrm{O}$ group is negative and its absolute value decreases by decreasing stereoregularity (Table 6).

In the case of polyvinyl ethers, $[\Phi]_{\mathrm{D}}$ decreases by decreasing stereoregularity 22 (Table 7 ) as in the poly- $\alpha$-olefins; the agreement is, however,

Table 6. Contributions to $[\Phi]_{\mathrm{D}^{25(a)}}$ by $n \rightarrow \pi^{*}$ electronic transition of the $>\mathrm{C}=\mathrm{O}$ chromophoric system and by background rotation in poly-[(S)-3-methyl-pentyl]-vinyl-ketone ${ }^{(b)}$

\begin{tabular}{l|c|c|c|c}
\hline \multicolumn{1}{c|}{$\begin{array}{c}\text { Polymerization } \\
\text { process }\end{array}$} & $\begin{array}{c}\text { Polymer } \\
\text { stereoregularity }\end{array}$ & $\begin{array}{l}{[\Phi]_{\mathrm{D}^{25(c)}}} \\
\text { experimental }\end{array}$ & $\begin{array}{c}{[\Phi]_{\mathrm{D}^{25(c)}}} \\
\text { background }\end{array}$ & $\begin{array}{c}{[\Phi] \mathbf{D}^{25(c, d)}} \\
(>\mathrm{G}=\mathbf{O}) \\
n \rightarrow \pi^{*}\end{array}$ \\
\hline $\begin{array}{l}\text { Anionic(e) } \\
\text { (pontaneous }\end{array}$ & $\begin{array}{l}\text { probably radical) } \\
\text { practically } \\
\text { absent }\end{array}$ & $+\mathbf{1 1 . 7}$ & $+\mathbf{2 8 . 5}$ & -16.8 \\
\hline
\end{tabular}

(a) In $\mathrm{CHCl}_{3}$ solution.

(b) Polymerized monomer optical purity $95 \%$.

(c) Referred to one monomeric unit.

(d) Calculated assuming $\lambda_{\mathrm{b}}$ background $=190 \mathrm{~m} \mu$ and $\mathrm{K}$ background $=8 \cdot 88 \cdot 10^{-6}$ for the sample of low stereoregularity, and $6 \cdot 55.10^{-6}$ for the atactic sample.

(e) Initiator $\mathrm{LiAlH}_{4}$.

Table 7. Relationship between optical rotation and stereoregularity in poly-[(S)-2-methylbutyl]-vinyl-ether ${ }^{(a)}$

\begin{tabular}{|c|c|c|c|c|c|}
\hline Fraction $^{(b)}$ & $\begin{array}{l}m . p \\
\left({ }^{\circ} \mathbf{C}\right)\end{array}$ & $\begin{array}{l}I . R^{(d)} \\
\text { crystallinity } \\
\text { index }\end{array}$ & {$[\Phi]_{\mathrm{D}^{25(e, f)}}$} & $\underset{(\mathrm{m} \mu)}{\lambda_{\max }{ }^{(h)}}$ & {$[\Phi]_{\lambda_{\max }}^{27}{ }^{(e, g)}$} \\
\hline $\begin{array}{l}\text { Acetone sol. } \\
\text { Acetone ins., diethyl ether sol. } \\
\text { Diethyl ether ins., benzene sol. }\end{array}$ & $\begin{array}{c}<25 \\
115-120^{(c)} \\
135-140^{(c)}\end{array}$ & $\begin{array}{l}0 \cdot 48 \\
0 \cdot 53 \\
0 \cdot 87\end{array}$ & $\begin{array}{l}+5 \cdot 5 \\
+5 \cdot 9 \\
+6 \cdot 5\end{array}$ & $\begin{array}{l}258 \\
244 \\
222\end{array}$ & $\begin{array}{l}+21 \cdot 1 \\
+31 \cdot 1 \\
+63 \cdot 8\end{array}$ \\
\hline
\end{tabular}

(a) Polymerized monomer optical purity $>99 \%$

(b) Obtained by boiling solvent extraction.

(c) Determined by i.r. spectroscopy.

(d) DB $827 \mathrm{~cm}^{-1} / \mathrm{D}_{\mathrm{B}} 771 \mathrm{~cm}^{-1}$.

(e) Referred to one monomeric unit.

(f) In toluene solution.

(g) In $n$-heptane solution.

(h) Wavelength corresponding to the maximum of the o.r.d. curve. 


\section{OPTICAL DISPERSION IN SYNTHETIG POLYMERS}

occasional because in polyvinyl ethers $[\Phi]_{\mathrm{D}}$, as shown by o.r.d. both of polymers and models, is given by the contributions of opposite sign of at least two chromophoric systems. The above contributions vary probably to a different extent with stereoregularity.

Investigating complexes both of polymers ${ }^{22}$ and models ${ }^{16}$ with Lewis acids it has been possible to attribute the negative contribution to the $n \rightarrow \sigma^{*}$ transition ${ }^{23}$ of the ethereal oxygen both in III $(n=0)$ and III $(n=1)$. If we admit that the positive contribution is chiefly given by the chromophoric systems connected with the hydrocarbon back bone, we must conclude that this last contribution is more influenced by the stereoregularity than the contribution arising from the $n \rightarrow \sigma^{*}$ transition of the ethereal oxygen. For the above reason in the case of III $(n=1)$ where the o.r.d. curve shows a maximum arising from the superimposition of the contributions of opposite sign to the rotation, the wavelength of the maximum is displaced toward shorter wavelengths by increasing the stereoregularity. In this case the wavelength of the maximum can be taken as an indication of the relative stereoregularity ${ }^{24}$ of the different fractions ( Table 7).

From the above discussion we can conclude that, in general, relationships exist between rotatory power and stereoregularity in vinyl polymers and hence relationships between conformational equilibria and stereoregularity; however the existence of the above relationships can be proposed only after a thorough investigation of o.r.d. in the largest possible wavelength range, confirming the origin of the maxima by c.d. measurements, and not on the basis of $[\Phi]$ measured only at a few wavelengths.

\section{RELATIONSHIP BETWEEN [ $\Phi]$ AND CONFORMATION}

Interesting indications on the relationships between $[\Phi]_{\lambda^{-}}$and polymer chain conformation have been obtained in the case of poly- $\alpha$-olefins on the basis of conformational analysis, semi-empirical calculations of optical activity per monomeric unit ${ }^{6}$, and statistical mechanical calculation of the macromolecular conformation ${ }^{25}$.

Conformational analysis, carried out according to well-established methods used in low-molecular-weight compounds ${ }^{2}$, has shown that in the case of isotactic polymers IV $(n=0)$ and IV $(n=1)$, in which large differences in $[\Phi]$ have been observed between polymers and low-molecular-weight models, only two conformations having highly positive and one having highly negative optical rotation are allowed when the asymmetric carbon atoms of the lateral chains has (S) absolute configuration (Table 8 ). In an ideal isotactic polymer the allowed conformations of the monomeric units can give rise only to a left-handed or to a right-handed helical conformation of the principal chain. Despite the small energy difference, mainly of entropic origin, calculated for monomeric units included in left-handed and righthanded helical conformation of principal chain sections, the comparison between $[\Phi]$ calculated by a semi-empirical method ${ }^{2}$, which gives excellent results in the case of low-molecular-weight paraffins, and experimental value shows that helical conformation of the thermodynamically-favoured screw sense largely prevails - at least in the case of IV $(n=0)$ and IV $(n=1)$ (Table $9)^{25}$. Statistical mechanical calculations give a consistent explanation of the 
P. PINO, P. SALVADORI, E. GHIELLINI and P. L. LUISI
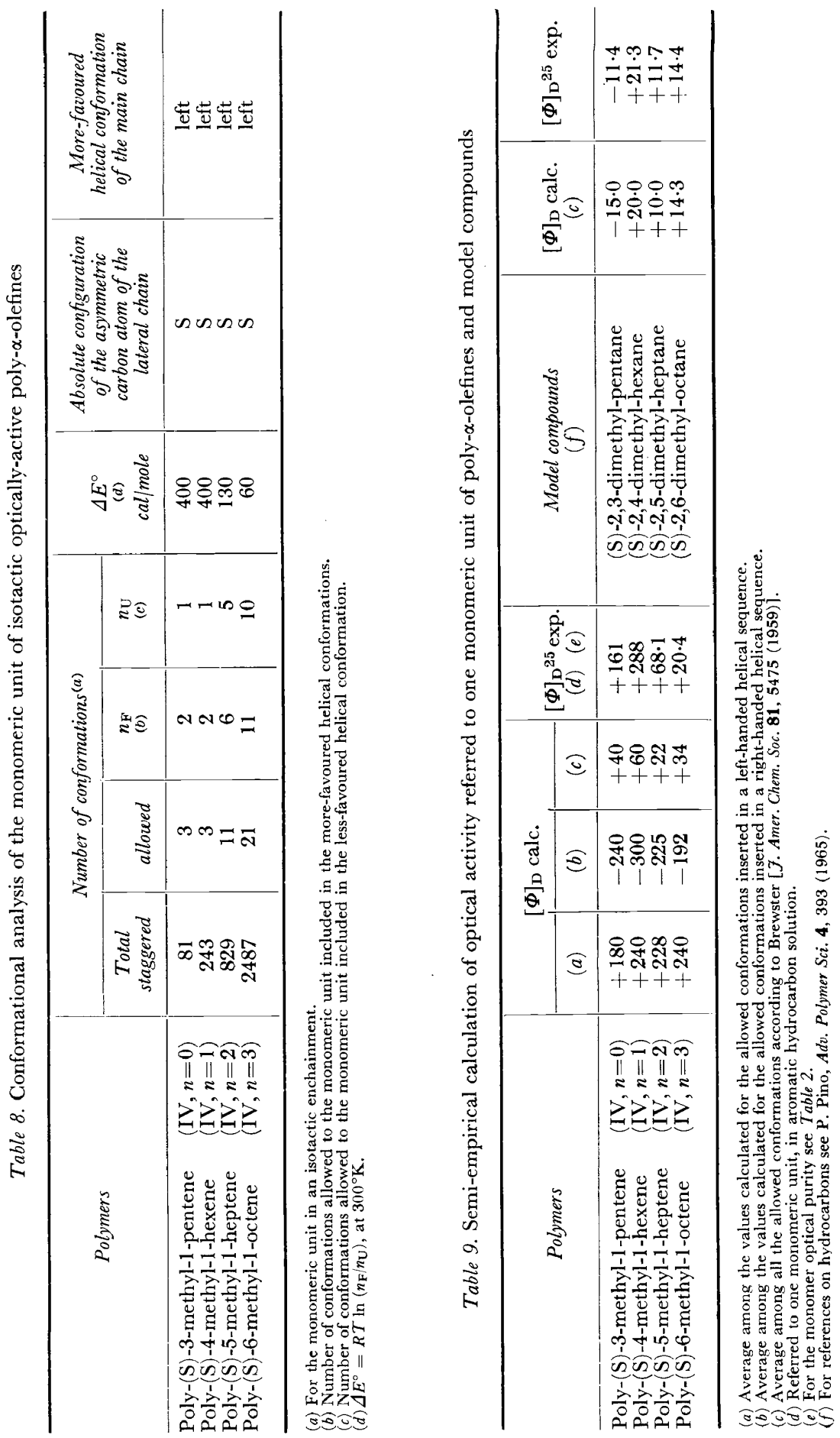
above facts and in the case of completely isotactic poly-(S)-4-methyl-1hexene [IV $(n=1)]$ yield the following very detailed picture: the macromolecules are formed by relatively-long left-handed helical sections, the average length of which corresponds at $300^{\circ} \mathrm{K}$ to about 24 monomeric units, alternated with short right-handed helical sections the average length of which corresponds to 2-3 monomeric units 3 (Luisi, Pino 1968). The "conformational reversals", connecting sections spiralled in opposite screw senses, continuously flow along the main chain because of the low potential barriers existing between different conformations. As a consequence the spiralled sections continuously change their length, only the average length of more favoured and less favoured helical sections remaining constant at a given temperature. The differences between the energy per monomeric unit included respectively in left-handed and right-handed helical conformation is $300-500$ calories at $300^{\circ} \mathrm{K}$, not very far from that calculated on the basis of purely entropic factors, admitting the same statistical weight for each allowed conformation. The average energy of the couple of monomeric units involved in the conformational reversals is $800-1100$ calories per monomeric unit higher than that of the average between the energies of couples of monomeric units included respectively in the thermodynamically more favoured and less favoured helical sections ${ }^{3}$ (Luisi, Pino 1968).

Shifting from a completely isotactic macromolecule to a macromolecule containing in the main chain a certain number of configurational inversions, a decrease in the prevalence of the thermodynamically most favoured screw sense is expected ${ }^{3}\left(\right.$ Luisi $\left.^{3}\right)$. These theoretical aspects could give a plausible explanation of the experimentally-observed decrease of the $[\Phi]$ by decreasing stereoregularity.

The above model is in agreement with the optical rotation experimentally measured in the solid state ${ }^{26}$ where the existence of helical conformation has been clearly demonstrated by X-ray analysis. Furthermore it has enabled us to foresee correctly the results of the following different experiments, some of which are still in progress.

According to the model, the high optical activity observed in the polymers IV $(n=0,1)$ is due to a particular position of the conformational equilibrium in which conformations having high rotation of the same sign largely prevail. The same phenomenon should occur in low-molecular-weight paraffins, in which only few conformations having high optical rotation of the same sign are allowed.

This situation can be foreseen by conformational analysis for the (3S; $5 \mathrm{~S})$-2,2,3,5-tetramethylheptane for which only one conformation having $[\Phi]_{\mathrm{D}}-180^{\circ}$ is allowed and (3R: $\left.5 \mathrm{~S}\right)-2,2,3,5$-tetramethylheptane for which only two conformations having respectively $+180^{\circ}$ and $+60^{\circ}$ are allowed ${ }^{27}$. As shown in Table 10 the values found for the optically-pure compounds are respectively $-100^{\circ}$ and $+140^{\circ}$. These values are of the same order of magnitude of rotation found in IV $(n=0,1)$, corresponding to the rotation calculated for the allowed conformations of their monomeric units included in left-handed helical sections of the macromolecule.

The existence of helical conformations in solution seems to be confirmed also by the optical activity of copolymers of optically-active $a$-olefins with 
P. PINO, P. SALVADORI, E. CHIELLINI and P. L. LUISI

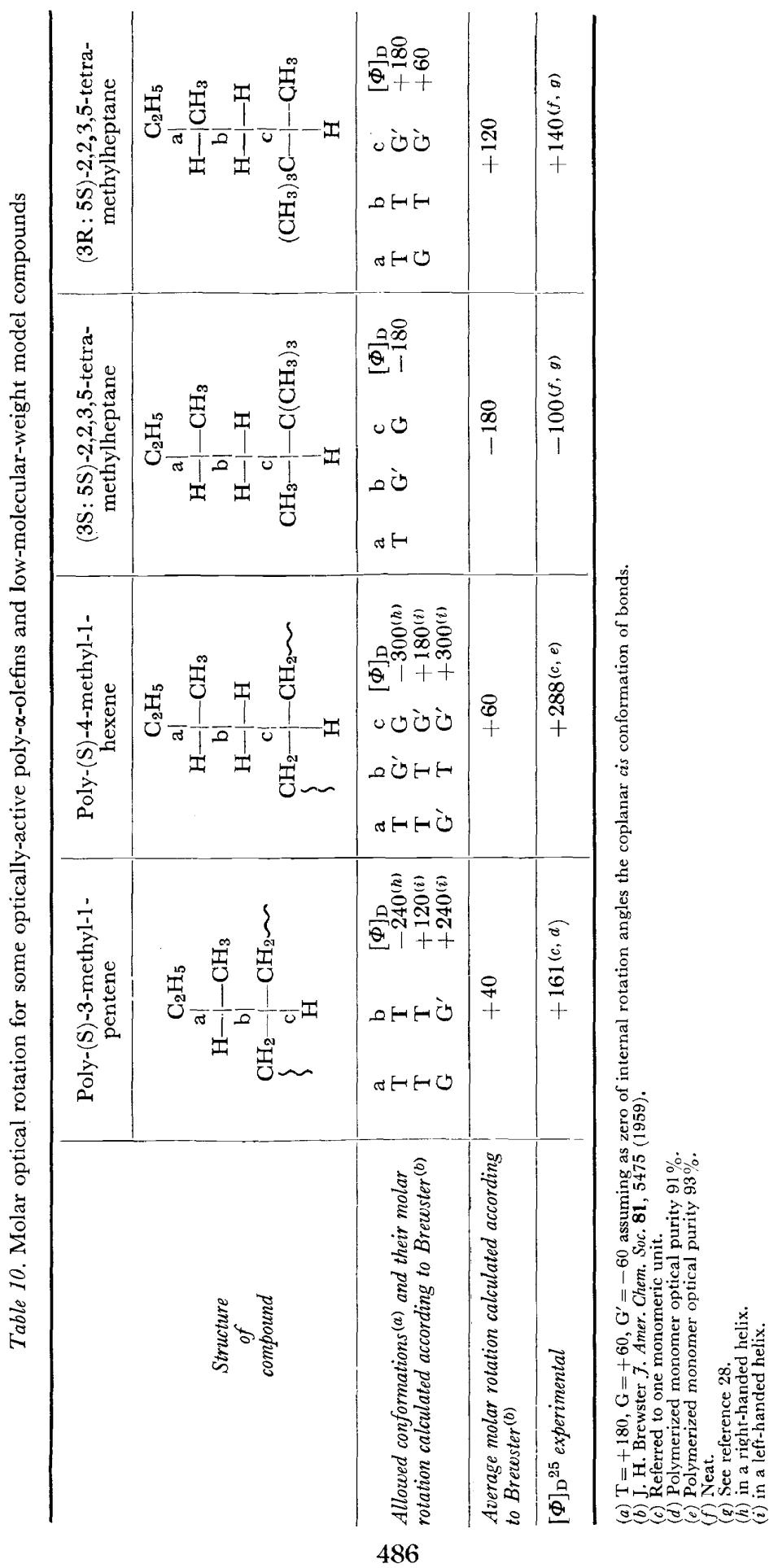




\section{OPTICAL DISPERSION IN SYNTHETIC POLYMERS}

monomers not containing asymmetric carbon atoms as 4-methyl-1-pentene and styrene.

(S)-4-methyl-1-hexene has been copolymerized with different amounts of 4-methyl-1-pentene and the acetone-insoluble, ethyl acetate-soluble fraction has been investigated 28 .

The amount of 4-methyl-1-pentene units present in the fraction was determined by i.r. analysis. Optical activity of the fraction was compared with that of a mixture of acetone-insoluble, ethyl acetate-soluble poly-(S)-4methyl-1-hexene and acetone-insoluble, ethyl acetate-soluble poly-4-methyl1-pentene containing a corresponding percentage of (S)-4-methyl-1-hexene and 4-methyl-1-pentene monomeric units.

Table 11. Comparison between optical rotation in cyclohexane solution of some samples of copolymer $^{(a)}$ (S)-4-methyl-1-hexene $(b) / 4$-methyl-1-pentene and mixtures of the two homopolymers $^{(d)}$ having the same composition

\begin{tabular}{c|c|c|c|c}
\hline $\begin{array}{c}\text { Composition of copolymer } \\
\text { samples and homopolymer } \\
\text { mixtures } \\
\begin{array}{c}\text { of }(\mathrm{S})-4-\text { methyl-1- } \\
\text { hexene-m.u. }(c)\end{array}\end{array}$ & $\begin{array}{c}{[a]_{\mathrm{D}}{ }^{25}} \\
\text { copolymer }\end{array}$ & $\begin{array}{c}{[a]_{\mathrm{D}}^{25}} \\
\text { homopolymers } \\
\text { mixture }\end{array}$ & {$[\Phi]_{\mathrm{D}}{ }^{25(\rho)}$} & {$[\Phi]_{\mathrm{D}}^{25(f, g)}$} \\
\hline $71 \cdot 0$ & +239 & +188 & +316 & +165 \\
$48 \cdot 1$ & +210 & +130 & +396 & +140 \\
24.9 & +147 & +71 & +515 & +89 \\
\hline
\end{tabular}

(a) Acetone ins., ethyl acetate sol. fraction.

(b) Polymerized monomer optical purity $93 \%$.

(c) (S)-4-methyl-1-hexene m.u. (S)-4-methyl-1-hexene m.u. + 4-methyl-1-pentene m.u

- 100 determined by i.r. spectroscopy, taking for poly-

(S) -4-methyl-1-hexene D B $964 \mathrm{~cm}^{-1}$ and for poly-4-methyl-1-pentene $\mathrm{D}_{\mathrm{B}} 918 \mathrm{~cm}^{-1}$.

(d) Acetone ins., ethyl acetate sol. fractions.

(e) Referred to one monomeric unit of poly-(S)-4-methyl-1-hexene, calculated assuming that in the copolymer the optical rotation derives only from (S)-4-methyl-1-hexene monomeric unit.

(f) Referred to one monomeric unit of poly-4-methyl-1-pentene, calculated attributing to the (S)-4-methyl-1hexene monomeric unit in the copolymer $[\Phi] \mathrm{D}^{25}+249$, corresponding to that of poly-(S)-4-methyl-1hexene sample used for the homopolymers mixture.

(a) Value calculated by the Brewster method for the allowed conformation of 4-methyl-1-pentene monomeric unit inserted in a left-handed helical sequence $[\Phi] \mathrm{D}+240$.

Preliminary data reported in Table 11 show that the specific rotation of the copolymers is much higher than that of the mixture of the two homopolymers. Attributing all the optical activity to the (S)-4-methyl-1-hexene monomeric units present in the copolymer, the value of $[\Phi] \mathrm{D}^{25}$ found for them is much higher than that ever found for the most isotactic poly- $(\mathrm{S})-4-$ methyl-1-hexene ${ }^{3}$ (Pino 1965) prepared up to now. Therefore the 4-methyl1-pentene units must contribute to the optical activity of the copolymers.

Supposing that (S)-4-methyl-1-hexene monomeric units have the same optical activity in the copolymer and in the homopolymer having the same solubility behaviour of the copolymer, $[\Phi]_{D}$ values referred to one 4-methyl1 -pentene monomeric unit are found which decrease with increasing percent of 4-methyl-1-pentene in the copolymer. The above values are of the same sign and of the same order of magnitude, calculated by the Brewster method ${ }^{2}$, for the allowed conformation of 4-methyl-1-pentene monomeric unit included in a left-handed helical section of poly-(S)-4-methyl-1-hexene.

Interesting results have been also obtained in the copolymerization of (R)-3,7-dimethyl-1-octene and styrene ${ }^{29}$, comparing the o.r.d. and c.d. 


\section{P. PINO, P. SALVADORI, E. CHIELLINI and P. L. LUISI}

Table 12. Comparison between optical rotatory power of some fractions of a copolymer (R)-3,7-dimethyl-1-octene ${ }^{(a)}$ /styrene and a low-molecular-weight model compound: (3S: 9S)-3,9-dimethyl-6-phenyl-undecane ${ }^{(b)}$

\begin{tabular}{l|c|c|c}
\hline \multicolumn{2}{c|}{ Copolymer(c) } & & Model compound \\
\hline \multicolumn{1}{c|}{ Fraction $^{(d)}$} & $\begin{array}{c}\text { Copolymer composition, } \\
(\%) \text { styrene m.u. } \\
(e)\end{array}$ & $\begin{array}{c}{[a] \mathrm{p}^{25}} \\
(\mathrm{~g})\end{array}$ & $\begin{array}{c}{[\mathrm{a}] \mathrm{p}^{25}} \\
(\mathrm{f})\end{array}$ \\
\hline & $\begin{array}{c}42 \cdot 0 \\
\text { Acetone sol. }\end{array}$ & $-27 \cdot 1$ & \\
$\begin{array}{l}\text { Acetone ins., diethyl ether sol. } \\
\text { Diethyl ether ins., cyclohexane sol. }\end{array}$ & $\mathbf{1 7 \cdot 9}$ & $-66 \cdot 6$ & +14.8 \\
\hline
\end{tabular}

(a) Polymerized monomer optical purity $75 \%$.

(b) Prepared from (S)-1-chloro-3-methylpentane having $[\alpha]]^{25}+19 \cdot 0$ (neat), optical purity $95 \%$.

(c) Monomer mixture composition $=\frac{\text { moles sytrene }}{\text { moles styrene }+ \text { moles }(\mathrm{R})-3,7 \text {-dimethyl-1-octene }} \cdot 100=4 \cdot 75$.

(d) Obtained by boiling-solvent extraction.

(e) $\frac{\text { styrene m.u. }}{\text { styrene m.u. }+(\mathrm{R})-3,7 \text {-dimethyl-1-octene m.u. }} 100$ estimated by u.v. spectra taking for $\varepsilon$ (polystyrene) $262 \mathrm{~m} \mu$ $=230$, for $\varepsilon[$ poly- $(\mathrm{R})-3,7$-dimethy1-1-oetene $262 \mathrm{~m} \mu=0$.

(f) In $n$-heptane.

(g) In cyclohexane.

of the copolymer with the o.r.d. and c.d. of (3S: 9S)-3,9-dimethyl-6-phenylundecane which, in our opinion, is a suitable low-molecular-weight model.

The acetone-insoluble, diethyl ether-soluble fraction of the copolymers (Table 12) which, on the basis of a very rough quantitative analysis based on the u.v. maximum at $262 \mathrm{~m} \mu^{30}$ contained about $14 \%$ by weight of styrene, was used for o.r.d. and c.d. measurements. A multiple Cotton effect appears in the region of $260 \mathrm{~m} \mu$ which has been confirmed by c.d. measurement ${ }^{29}$ (Figure 4 ).

The same multiple Cotton effect in the region of the forbidden $\pi \rightarrow \pi^{* 31}$ transition of the benzene chromophore has been found also in the lowmolecular-weight model according to the fact that the phenyl group is

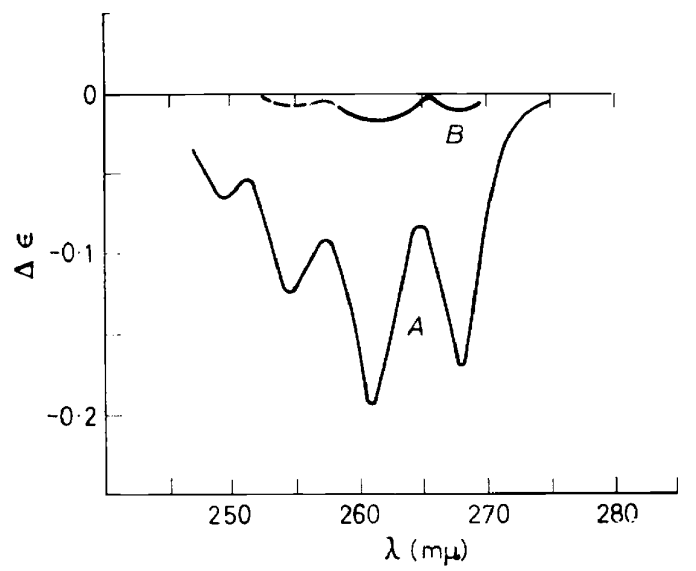

Figure 4. Circular dichroism curves: $(A)$ (R)-3,7-dimethyl-1-octene-styrene copolymer containing $17 \cdot 9 \%$ of styrene m.u. $(B)(3 R: 9 R)-3,9$-dimethyl-6-phenyl-undecane calculated on the basis of measurements carried out on its antipode. 


\section{OPTICAL DISPERSION IN SYNTHETIC POLYMERS}

placed in both cases in an asymmetric environment. However $\Delta \epsilon$ of c.d. maxima at 267 and $262 \mathrm{~m} \mu$ of the polymers are at least 10 times higher than corresponding $\Delta \epsilon$ in the model. In our opinion the relatively large values of $\Delta \epsilon$ found for the polymer in the region of about $260 \mathrm{~m} \mu$ can be suitably explained by assuming that the styrene monomeric units are inserted in helical sections of the macromolecule principal chain which is prevailingly spiralled in a single screw sense, so that the styrene monomeric units, for thermodynamic reasons, assume few conformations having high optical activity of the same sign as indicated by the relatively large Cotton effect. However the above explanation should be regarded as preliminary and more experimental data are needed for a better understanding of the above facts.

\section{Final remarks}

In the present paper we have considered some results obtained in the field of optically-active synthetic polymers: in general optical activity is highly dependent on structure in vinyl polymers when asymmetric carbon atoms are present in the lateral chains in $\alpha$ or $\beta$ position with respect to the principal chain. In these cases a remarkable dependence of optical activity on stereoregularity has been found. The relationship between optical activity and conformations of the macromolecules has been clarified only in the case of poly- $\alpha$-olefins. For these polymers a model has been proposed which is consistent with all the experimental facts so far obtained and suggests further experiments which should give us a deeper understanding of the behaviour of this type of polymers in solution. The presence of helical conformation which has been ascertained in solution for poly- $\alpha$-olefins, has not been proved up to now for the other high polymers investigated; a deeper knowledge of the conformational analysis of oxygenated compounds and suitable semi-empirical calculations of optical activity for the same compounds should favour further progress in this field.

In conclusion the results achieved up to now show that optical activity, o.r.d. and c.d. are very powerful tools for the investigation of macromolecular conformation in solution and further interesting progress may be expected in the investigation of both optically-active addition and condensation polymers.

\section{Acknowledgements}

The authors express their gratitude to Prof. L. Lardicci, Dr. F. Ciardelli, Dr. O. Pieroni and Dr. C. Carlini for their kind permission to report in this paper some not yet published data. Their advice during the preparation of this paper is also very gratefully appreciated.

Particular acknowledgement is due to the staff of the Soc. Jouan of Paris for their assistance in performing some c.d. measurement by a RousselJouan Dichrograph CD 185.

\section{Notes added in proof}

\section{Refers to page 471}

In a recent paper [Makromol Chem. 105, 18 (1967] K. J. Liu, J. S. Lignowski and R. Ullman have investigated polymethacrylates of optically 
active alcohols and attribute the features of the u.v. spectra of the isotactic poly-methylmethacrylate ${ }^{11}$ to the presence of terminal phenyl groups in the macromolecules. However, A. M. Liquori does not agree with the above explanation, as the polymers used by him did not contain low molecular weight fractions.

\section{Refers to page 476}

Ultraviolet spectra of poly-(S)-lactic acid and its low molecular weight models have been recently investigated by $M$. Goodman and M. D'Alagni [Polymer Letters 5, 515 (1967)] and by R. C. Schulz and A. Guthmann [Polymer Letters 5, 1099 (1967)].

\section{References}

1 M. V. Volkenstein. Configurational Statistics of Polymer Chains, Interscience, New York, 1963 , p. 139.

2 J. H. Brewster. J. Amer. Chem. Soc. 81, 5475 (1959).

3 P. Pino. Adv. Polymer Sci. 4, 393 (1965);

P. L. Luisi, Polymer Letters (1968), in the press.

P. L. Luisi and R. Rino. J. Chem. Phys. (1968), in the press.

4 R. C. Schulz and E. Kaiser. Adv. Polymer Sci. 4, 236 (1965);

M. Goodman, A. Abe, and Y.L. Fan, in Macromolecular Reviews 1, 1 (1967).

5 I. Tinoco. Adv. Chem. Phys. 4, 113 (1962);

R. A. Harris. J. Chem. Phys. 43, 959 (1965);

R. Ullman. J. Polymer Sci. C, 12, 317 (1966).

6 P. Pino, F. Ciardelli, G. P. Lorenzi, and G. Montagnoli. Makromol. Chem. 61,207 (1963).

7 See for instance G. Holzwarth and P. Doty. J. Amer. Chem. Sac. 87, 218 (1965).

8 W. Moffitt. J. Chem. Phys. 25, 467 (1956);

W. Moffitt, D. D. Fitts, and J. G. Kirkwood. Proc. Nat. Acad. Sci. 43, 723 (1957);

E. R. Blout, in Optical Rotatory Dispersion by G. Djerassi, McGraw-Hill, 1960.

9 F. Ciardelli, E. Benedetti, and O. Pieroni. Makromol. Chem. 103, 1 (1957).

10 W. M. Pasika and R. Brandon. Polymer 6, 503 (1965).

11 M. D'Alagni, P. De Santis, A. M. Liquori, and M. Savino. Polymer Letters 2, 925 (1964).

12 See for instance W. D. Closson and P. Haug. J. Am. Chem. Soc. 86, 2384 (1964).

13 P. Pino, G. P. Lorenzi, and L. Lardicci. Chim. e l'Ind. 42, 712 (1960);

P. Pino, G. P. Lorenzi, E. Chiellini, and P. Salvadori. Atti Accad. Nazl. Lincei, Rend. [8], 39, 196 (1965).

14 O. Pieroni, F. Ciardelli, C. Botteghi, L. Lardicci, P. Salvadori, and P. Pino. I.U.P.A.C. Symposium on Macromolecular Chemistry, Bruxelles, 1967, Preprint 8/23.

15 P. Maroni. Ann. Chim. 2, 757 (1957).

16 P. Salvadori, L. Lardicci, G. Consiglio, and P. Pino. Tetrahedron Letters 5343 (1966).

17 F. I. Klabunovsky, M. I. Shvartsman, and Yu. I. Petrov. Vysokomol. Soed. 6, $1579(1964)$; Izvest. Akad. Nauk SSSR 223 (1966).

${ }^{18}$ E. Chiellini, M. Osgan, P. Pino, and P. Salvadori, in preparation.

19 R. C. Schulz and J. Schwaab. Makromol. Chem. 87, 90 (1965).

20 O. Pieroni, F. Giardelli, P. Salvadori, and P. Pino, in preparation.

21 L. Lardicci, P. Salvadori, C. Botteghi, and P. Pino. Chem. Commun. 381 (1968).

22 P. Pino, G. P. Lorenzi, and E. Chiellini. Symposium on Macromolecular Chemistry, Prague, 1965. Preprint, 455.

23 S. F. Mason. Quart. Reviews 15, 287 (1961).

24 P. Pino, P. Salvadori, and E. Chiellini, in preparation.

25 P. Pino and P. L. Luisi. J. Chim. phys. 65, 130 (1968).

26 P. Pino, G. P. Lorenzi, and O. Bonsignori. Chim. e l'Ind. 48, 760 (1966).

27 S. Pucci, M. Aglietto, P. L. Luisi, and P. Pino. J. Amer. Chem. Soc. 89, 2787 (1967).

28 F. Ciardelli, C. Carlini, E. Benedetti, and P. Pino, in preparation.

29 P. Pino, C. Carlini, E. Chiellini, F. Ciardelli, and P. Salvadori. Chim. e l'Ind. 50, 257 (1968).

30 G. Loux and G. Weill. J. Chim. phys. 61, 484 (1964).

31 L. Verbit. J. Amer. Chem. Soc. 88, 5340 (1966). 